\title{
Assessment of the educational environment of physiotherapy students at the University of Rwanda using the Dundee Ready Educational Environment Measure (DREEM)
}

\author{
G Urimubenshi, MScPT; J Songa, BScPT; F Kandekwe, BScPT \\ Department of Physiotherapy, College of Medicine and Health Sciences, University of Rwanda, Kigali, Rwanda
}

Corresponding author: G Urimubenshi (ugerardus@gmail.com)

Background. Getting students' feedback regarding their experience of their educational environment (EE) is important.

Objectives. To explore how physiotherapy students at the University of Rwanda (UR) feel about their EE.

Methods. A descriptive quantitative cross-sectional study design with a census sampling strategy involving all physiotherapy students at UR was used. The Dundee Ready Educational Environment Measure was administered to 77 physiotherapy students in March 2015, to collect data that were analysed using the Statistical Package for the Social Sciences version 20 (IBM Corp., USA). The frequency distribution, mean, standard deviation and percentages were calculated, and the $\chi^{2}$ test was performed to assess whether responses showed significant variance according to level of study and gender. The level of significance ( $p$-value) was set at 0.05 .

Results. The overall mean score on the 50 items was $62.20 \%$. Students' perception of learning scored the highest, with $66.58 \%$, followed by students' perception of atmosphere with $65.08 \%$, students' perception of teachers with $61.11 \%$ and students' academic self-perception with $57.78 \%$. The domain of students' social self-perception scored the least, with $56.50 \%$. All the domains scored positively toward the EE. There was no significant difference between male and female students, or between first-, second-, third- and fourth-year students regarding their perceptions of the EE.

Conclusion. The physiotherapy students perceived UR as providing a sound EE. However, the data showed that there is a need for improvement in all five subscales of the learning environment at UR. Similar studies from other academic programmes at UR and other academic institutions in Rwanda are encouraged.

Afr J Health Professions Educ 2017;9(3):103-106. DOI:10.7196/AJHPE.2017.v9i3.828

An educational environment (EE) is made up of three major components: the physical environment, the emotional climate and the intellectual climate. ${ }^{[1]}$ The EE of professional health training is mainly determined by the interactions between different stakeholder groups and the organisational structures of the environment. ${ }^{[2]}$ Ideally, the EE should foster intellectual activities and academic progression, while simultaneously encouraging friendliness, co-operation and support. It is important to get students' feedback on how they experience their EE. ${ }^{[3]}$ Different studies aiming to assess medical or health sciences students' perceptions of their learning environment have been conducted in many developed and developing countries, such as the UK, Saudi Arabia, Canada, India and Malaysia. ${ }^{[4]}$

There is only one programme of physiotherapy education in Rwanda. This programme is hosted by the University of Rwanda (UR), and began in December 1996 with the vision of becoming a centre of excellence in training physiotherapy professionals in Rwanda and the whole East African region. Despite anecdotal feedback through informal conversations between the students and their lecturers, however, the EE as perceived by the UR physiotherapy students has never been formally assessed. This study aimed to explore how physiotherapy students at UR feel about their EE, to identify domains of strength and weakness, and to suggest ways to improve the students' experience.

\section{Methods Study design \\ A descriptive cross-sectional study design was used.}

\section{Materials and subjects}

The Dundee Ready Education Environment Measure (DREEM) was developed by Roff $e$ t al. ${ }^{[5]}$ as a generic instrument for measuring students' perceptions of undergraduate health professions curricula. It was administered to collect this data and information on characteristics, including age, gender and year of study. The DREEM instrument consists of 50 statements, and gives a universal score of a maximum of 200. It is capable of measuring five separate elements directly relevant to the educational environment: students' perception of learning (SPOL), students' perception of teachers (SPOT), students' academic self-perceptions (SASP), students' perception of atmosphere (SPOA) and students' social self-perceptions (SSSP). ${ }^{[5]}$

The DREEM questionnaire has been successfully tested for its internal validity and reliability. ${ }^{[6]}$ The study population consisted of all 82 registered physiotherapy students at the College of Medicine and Health Sciences (CMHS) for the academic year 2014 - 2015. A census sampling strategy was used, but four students who assisted in data collection were excluded, and one student was not available during the data-collection period. Therefore, the study sample consisted of 77 participants. 


\section{Data collection procedure}

The DREEM questionnaire was administered to physiotherapy students at UR in March 2015, and scored according to standard guidelines. ${ }^{[7]}$ The DREEM questionnaire consists of five-point Likert-scale responses to statements, as follows: strongly agree (4), agree (3), neutral (2), disagree (1) and strongly disagree (0). The score is reversed for negatively oriented statements. Items with a mean score greater than 3 represent strong areas; items with a mean score of less than 2 indicate problematic areas; and items with mean scores between 2 and 3 indicate areas that could be improved.

\section{Data analysis}

The Statistical Package for the Social Sciences (IBM Corp., USA) version 20 was used to analyse the data. The frequency distribution, mean and standard deviation (SD) were calculated, and the $\chi^{2}$ test was performed to assess whether responses showed significant variance according to level of study and gender $(p=0.05)$.

The mean score of each domain and the overall mean were calculated, and interpreted using the methods of Roff ${ }^{[7]}$ as follows: 0 - $50(0-25 \%)=$ very poor environment; $51-100(26-50 \%)=$ multiple problems in the environment; $101-150(51-75 \%)=$ more positive than negative environment; and $151-200$ $(76-100 \%)=$ excellent environment.

\section{Ethics approval}

Ethical clearance and permission to conduct the study were respectively granted by the CMHS Institutional Review Board (ref. no. CMHS/ IRB/010/2015) and the principal of CMHS (ref. no. 641/UR-CMHS/15). The students were formally briefed about the study and the questionnaire in their classrooms, and were informed that participation was voluntary and that they had the right to withdraw from the study at any time. In addition to this, the questionnaire was anonymous. All the students who were contacted consented to take part in the study, and they were requested to provide their demographic details and to respond to each of the 50 statements.

\section{Results}

\section{Characteristics of participants}

Questionnaires were administered to 77 physiotherapy students, and all returned the questionnaires completed, corresponding to a response rate of $100 \%$. Table 1 reflects the distribution of the students across the 4 years of training.

Table 2 describes the overall DREEM score and mean score for each domain. The total mean scores across the five domains vary between $56.50 \%$ (SSSP) and $66.58 \%$ (SPOL). The overall score is $124.4 / 200(62.20 \%)$

Table 1. Distribution of respondents by gender and level of study $(N=77)$

\begin{tabular}{ll}
\hline Variable & $\boldsymbol{n}(\%)$ \\
\hline Gender & \\
Male & $53(68.83)$ \\
Female & $24(31.17)$ \\
Level & \\
Year 1 & $14(18.18)$ \\
Year 2 & $18(23.38)$ \\
Year 3 & $21(27.27)$ \\
Year 4 & $24(31.17)$
\end{tabular}

Table 2. DREEM mean score for all study participants $(N=77)$

\begin{tabular}{lll}
\hline & $\begin{array}{l}\text { Maximum } \\
\text { score }\end{array}$ & $\begin{array}{l}\text { Mean (\%) } \\
\text { SD }\end{array}$ \\
\hline Students' perceptions of learning (SPOL) & 48 & $31.96(66.58)$ \\
& & 0.30 \\
Students' perceptions of teachers (SPOT) & 44 & $26.89(61.11)$ \\
& & 1.42 \\
Students' academic self-perceptions (SASP) & 32 & $18.49(57.78)$ \\
& & 0.36 \\
Students' perceptions of atmosphere (SPOA) & 48 & $31.24(65.08)$ \\
& & 0.72 \\
Students' social self-perceptions (SSSP) & 28 & $15.82(56.50)$ \\
& & 0.16 \\
Overall DREEM score & 200 & $124.4(62.20)$ \\
DREEM = Dundee Ready Educational Environment Measure. & 4.40
\end{tabular}

(SD 4.40), meaning that the participants perceive their EE more positively than negatively.

The study also aimed to test if the responses varied according to the level of study or the gender of the participants. As shown by Tables 3 and 4 below, no association was found $(p>0.05)$.

\section{Discussion}

To the best of our knowledge, this is the first study providing information on the perceptions of physiotherapy students at UR of their EE. This study used a standardised questionnaire and a census sampling method. The results reflect the EE as experienced by physiotherapy students at UR, and may help different policy makers and physiotherapy lecturers at UR to generate responses for improvement.

With an overall DREEM score of 124.4/200 (62.2\%), the students rated the EE at UR as 'more positive than negative'. This study also indicated that the students perceived each of the five EE domains more positively than negatively.

It is not appropriate to fully compare this study with others, because of contextual dissimilarities and different sample sizes used. However, while contrasting and interpreting the scores against the guidelines proposed by the developers of the DREEM instrument, it emerged that this study has a common main finding with other similar studies conducted elsewhere, such as in India, ${ }^{[8]}$ Malaysia, ${ }^{[9]}$ Nigeria $^{[10]}$ and Sweden, ${ }^{[2]}$ for example. All these studies reported that students view their EE in general as more positive than negative, thereby having an optimistic view of their learning situation, lecturers, educational atmosphere and academic and social life.

The overall score (124.4/200) for the current study setting, which uses a student-centred learning approach, was higher than those found in Saudi Arabia (89/200), ${ }^{[11]}$ Canada (97/200), ${ }^{[12]}$ Bangladesh (110/200), ${ }^{[13]}$ India $(117 / 200)^{[8]}$ and Malaysia (118/200). ${ }^{[14]}$ It has been observed that students involved with innovative curricula (innovative in terms of providing a student-centred approach to education) tend to show more satisfaction with their learning environments, compared with students experiencing traditional curricula ${ }^{[15]}$ It is likely that the institutions that were studied in these countries offer conventional learning approaches. For instance, in one of the institutions, the College of Medicine at King Saud University, Saudi Arabia, the curriculum was reported as overcrowded and teacher centred. ${ }^{[11]}$ 
Table 3. Perception differences on EE in DREEM mean scores across years of study ( $N=77)$

\begin{tabular}{|c|c|c|c|c|c|}
\hline Domains & $\begin{array}{l}\text { Year } 1 \\
\text { Mean (\%) SD }\end{array}$ & $\begin{array}{l}\text { Year } 2 \\
\text { Mean (\%) SD }\end{array}$ & $\begin{array}{l}\text { Year } 3 \\
\text { Mean (\%) SD }\end{array}$ & $\begin{array}{l}\text { Year } 4 \\
\text { Mean (\%) SD }\end{array}$ & $p$-value \\
\hline SPOL & $32.08(66.83) 3.61$ & 32.02 (66.71) 4.156 & $31.62(65.88) 3.89$ & $31.47(65.56) 3.87$ & 0.970 \\
\hline SPOT & 25.95 (58.98) 3.121 & $25.57(58.11) 3.44$ & $27.34(62.14) 2.86$ & $28.68(65.18) 3.00$ & 0.912 \\
\hline SASP & $18.72(58.50) 2.68$ & $18.84(58.88) 2.80$ & $18.06(56.44) 2.74$ & $18.35(57.34) 2.78$ & 0.486 \\
\hline SPOA & $30.59(63.73) 3.80$ & $30.67(63.90) 4.95$ & $31.73(66.10) 4.37$ & $31.98(66.63) 4.40$ & 0.47 \\
\hline SSSP & $15.97(54.04) 2.57$ & $15.75(56.25) 2.85$ & $15.63(55.82) 3.06$ & $15.94(56.93) 3.12$ & 0.73 \\
\hline
\end{tabular}

However, the score found in the current study was lower than those found in Nigeria $(131 / 200),{ }^{[10]}$ Malaysia $(133 / 200),{ }^{[9]}$ Sri Lanka $(141 / 200)^{[16]}$ and Sweden (150/200). ${ }^{[2]}$ This may reflect that these institutions are fairly innovative in terms of providing a student-centred approach to education, ${ }^{[17]}$ and the physiotherapy lecturers at UR should explore how they can learn from good practices in those countries.

The highest score in this study was found in the domain of SPOL. Several factors could have contributed to this SPOL score. The physiotherapy curriculum in Rwanda adheres to the standards of the World Confederation of Physical Therapy, the Rwanda Allied Health Professions Council and the Higher Education Council of Rwanda. In addition, physiotherapy education in Rwanda emphasises a competence-based and student-centred learning approach.

The lowest mean score was found in the domain of SSSP. This finding is not surprising, as the majority of the physiotherapy students at UR do not have university accommodation, and live off-campus. This is a call to the UR administration to look for ways that the social welfare of the students can be improved.

In contrast with some others, ${ }^{[8,18]}$ this study revealed that there are no differences in the perceptions of EE between male and female students, or between first-, second-, third- and fourth-year students. Not having perception differences among the groups of students may indicate that the EE at UR is equally friendly to all students, and this may be a positive aspect of physiotherapy education in Rwanda.

\section{Study limitations}

The study has some limitations. The quantitative descriptive study design that was used does not provide participants with opportunities to tell their stories outside the boundaries of structured measurement scales, and therefore to bring depth and clarity to the understanding of experiences of EE. A mixed-method design would be better for such studies to evaluate EE.

\section{Conclusion}

The results of this study provide valuable clues as to how undergraduate physiotherapy students perceive their EE. Students were positive about teaching, their lecturers and educational atmosphere and their academic success, and had a good overall feeling regarding their social situation. Overall, students perceived that the institution provided a sound EE. However, the overall score of $62.20 \%$ indicates that there is a need for improvement of the learning environment of physiotherapy education at UR. Similar studies from other academic programmes at UR and other academic institutions in Rwanda using mixed-method designs are encouraged.
Table 4. Perception differences on EE in DREEM mean scores according to gender $(N=77)$

\begin{tabular}{|c|c|c|c|}
\hline Domains & $\begin{array}{l}\text { Males } \\
\text { mean (\%) SD }\end{array}$ & $\begin{array}{l}\text { Females } \\
\text { mean (\%) SD }\end{array}$ & $p$-value \\
\hline SPOL & $30.72(64.00) 3.35$ & $33.20(69.17) 3.18$ & 0.83 \\
\hline SPOT & $26.34(59.86) 3.71$ & $27.44(62.36) 4.22$ & 0.25 \\
\hline SASP & $19.01(59.41) 4.30$ & $17.97(56.16) 4.12$ & 0.88 \\
\hline SPOA & $30.78(64.13) 3.64$ & $31.70(66.04) 2.93$ & 0.73 \\
\hline SSSP & $15.72(56.14) 3.35$ & $15.92(56.86) 3.44$ & 0.16 \\
\hline \multicolumn{4}{|c|}{$p \leq 0.05$ is considered significant. } \\
\hline \multicolumn{4}{|c|}{$\begin{array}{l}\text { DREEM = Dundee Ready Educational Environment Measure; EE = educational environment; } \\
\text { SPOL = students' perceptions of learning; SPOT = students' perceptions of teachers; SASP = } \\
\text { students' academic self-perceptions; SPOA = students' perceptions of atmosphere; SSSP = students' } \\
\text { social self-perceptions. }\end{array}$} \\
\hline
\end{tabular}

Acknowledgements. The authors wish to express their gratitude to all physiotherapy students at UR who devoted their time to participate in the study. Author contributions. All authors conceived the study, analysed data, reviewed the manuscript and approved the final version of the manuscript. JS and FK collected data, and GU wrote the first draft of the manuscript and edited the final version.

Funding. None

Conflicts of interest. The authors declare that they have no conflict of interest.

1. Clapham M, Wall D, Batchelor A. Educational environment in intensive care medicine - use of Postgraduate Hospital EE Measure (PHEEM). Med Teach 2007;29(6):184-191. https://doi.org/10.1080/01421590701288580 2. Palmgren PJ, Lindquist I, Sundberg T, Nilsson GH, Laksov KB. Exploring perceptions of the educational environment among undergraduate physiotherapy students. Int J Med Educ 2014;5:135-146. https://doi org/10.5116/ijme.53a5.745

3. Abraham R, Ramnarayan K, Vinod P, Torke S. Students' perceptions of learning environment in Indian medica school. BMC Med Educ 2008;8(3):20-24. https://doi.org/10.1186/1472-6920-8-20

4. Al-Rukban MO, Khalil MS, Al-Zalabani A. Learning environment in medical schools adopting differen educational strategies. Educ Res Rev 2010;5(3):126-129.

5. Roff S, Mcaleer S, Harden RM, et al. Development and validation of the Dundee Ready Education Environment Measure (DREEM). Med Teach 1997;19(4):295-299. https://doi.org/10.3109/01421599709034208

6. Koohpayehzadeh J, Hashemi A, Soltani Arabshahi K, et al. Assessing validity and reliability of Dundee Ready Educational Environment Measure (DREEM) in Iran. Med J Islam Repub Iran 2014:28:60-68.

7. Roff S. The Dundee Ready Educational Environment Measure (DREEM), a generic instrument for measuring students' perceptions of undergraduate health professions curricula. Med Teach 2005;27(4):322-325. https://doi. org/10.1080/01421590500151054

8. Sunkad AM, Javali S, Shivapur Y, Wantamutte A. Health sciences students' perception of the educational environment of KLE University, India as measured with the Dundee Ready Educational Environment Measure (DREEM). J Educ Eval Health Prof 2015;12:37-40. https://doi.org/10.3352/jeehp.2015.12.37

9. Veasuvalingam B, Arzuman H. Physiotherapy students' perception of their educational environment: A study to identify the areas of concern for remedial measures at two schools of physiotherapy in Malaysia. Educ in Med J 2014;6(3):30-39. https://doi.org/10.5959/eimj.v6i3.233

10. Odole AC, Oyewole OO, Ogunmola OT. Nigerian physiotherapy clinical students' perception of their learning environment measured by the Dundee Ready Education Environment Measure Inventory. Int J High Ed 2014;3(2):83-91. https://doi.org/10.5430/ijhe.v3n2p83

11. Al-Ayed IH, Sheikh SA. Assessment of educational environment at the College of Medicine of King Saud University, Riyadh. East Mediterr Health J 2008;14(4):953-959.

12. Audinet K, Davy J, Barkham M. University quality of life and learning (UNIQoLL): An approach to student wellbeing, satisfaction and institutional change. J Further High Educ 2003;27(4):365-382. https://doi. org $/ 10.1080 / 0309877032000128073$ 
13. Nahar N, Talukder HK, Khan TH, Mohammad S, Nargis T. Students' perception of educational environmen of medical colleges in Bangladesh. BSMMU J 2010;3(2):97-102. https://doi.org/10.3329/bsmmuj.v3i2.7060

14. Arzuman H, Yusoff MSB, Chit SP. . Big Sib students' perceptions of the educational environment at the Schoo of Medical Sciences, Universiti Sains Malaysia, using Dundee Ready Educational Environment Measure (DREEM) Inventory. Malays J Med Sci 2010;17(3):40-47.

15. Said NM, Rogayah J, Hafizah A. A study of learning environments in the Kulliyyah (Faculty) of Nursing International Islamic University Malaysia. Malays J Med Sci 2009;16(4):15-24.

16. Perera D. The assessment of undergraduate physiotherapy education in Sri Lanka. Int J Sci Res Pub 2016;6(4):329-332.
17. Brown T, Williams B, Lynch M. The Australian DREEM: Evaluating student perceptions of academic learning environments within eight health science courses. Int J Med Educ 2011;2(2):94-101. https://doi.org/10.5116 ijme.4e66.1b37

18. Al-Naggar RA, Abdulghani M, Osman MT, et al. The Malaysia DREEM: Perceptions of medical students about the learning environment in a medical school in Malaysia. Adv Med Educ Pract 2014;5:177-184.

Accepted 14 December 2016 